\title{
Bibliotecas, Bibliofilia e Bibliografia: alguns apontamentos ${ }^{1}$
}

\author{
Libraries, Bibliophile and Bibliography: some approaches
}

\begin{abstract}
Diná Marques Pereira Araújo
Mestranda do Programa de Pós-Graduação em Ciência da Informação da Universidade Federal de Minas Gerais

- UFMG

Bibliotecária-documentalista da Universidade Federal de Minas Gerais - UFMG.

E-mail: dina-araujo@bu.ufmg.br
\end{abstract}

\begin{abstract}
Alcenir Soares dos Reis
Doutora em Educação pela Universidade Federal de Minas Gerais - UFMG.

Professora Associada da Escola de Ciência da Informação da Universidade Federal de Minas Gerais - UFMG.

E-mail: alcenir@eci.ufmg.br
\end{abstract}

\section{Resumo}

\begin{abstract}
Aborda sobre Bibliografia e suas relações com a Bibliofilia e a Biblioteconomia de Livros Raros. Apresenta autores que destacam as várias vozes e significados atribuídos à Bibliografia. Discorre sobre os repertórios bibliográficos apresentando exemplos de bibliografias da Bibliofilia a partir do século XVIII. Aponta um panorama da Bibliografia Material, anglo-saxã e sua influência na Biblioteconomia. Reflete sobre as correntes da bibliografia como campo do conhecimento necessário para a formação do bibliotecário-pesquisador de livros raros, antigos e especiais.
\end{abstract}

Palavras-chave: Bibliografia. Bibliografia Material. Livros Raros.

\begin{abstract}
Discusses about Bibliography and its relations with the Bibliophile and Rare Book Librarianship. Emphasizes the authors who talk about the various voices and meanings attributed to the Bibliography. Discusses the bibliographic repertoires providing examples of bibliographies directed to the Bibliophile. Points an overview of material bibliography, Anglo-Saxon, and its use by the Librarianship. Reflects on the currents of bibliography as a field of knowledge required for the formation of the librarian-researcher of rare books.
\end{abstract}

Keywords: Bibliography. Material bibliography. Rare books.

\footnotetext{
${ }^{1}$ Artigo foi apresentado no I Seminário Internacional "A Arte da Bibliografia: ferramentas históricas, problemas metodológicos e práticas contemporâneas" aos dias 04 de dezembro de 2014, na Universidade Federal do Rio de Janeiro (UFRJ), realizado pelo Programa de Pós-Graduação em Ciência da Informação/IBICT-UFRJ.
}

InCID: R. Ci. Inf. e Doc., Ribeirão Preto, v. 7, n. esp., p. 183-201, ago. 2016. 


\section{Apresentação}

As nominações para bibliotecas institucionais que resguardam acervos antigos e raros variam entre Obras Raras, Fundos Antigos, Biblioteca Histórica, Biblioteca Patrimonial e Coleções Especiais. Os autores Steven Kenneth Galbraith e Geoffrey Dayton Smith, em Rare Book Librarianship, denominam as coleções documentais patrimoniais, em instituições públicas de língua inglesa no século XX, como acervos de "Livros Raros e Coleções Especiais" (GALBRAITH \& SMITH, 2012, p.9). Os apontamentos em nossa apresentação estão voltados para o contexto dos acervos bibliográficos reconhecidos como especiais e raros.

As coleções especiais em bibliotecas institucionais são distintas dos demais acervos de uma biblioteca por sua constituição temática, finalidade, características materiais e significados patrimoniais para a instituição que as preservam. A política de desenvolvimento de acervo é outro fator que proporciona distinção para essas coleções ao estabelecer planos normativos para sistematizar formas de organização, conservação, aquisição, acesso, segurança, pesquisas e avaliação de coleção(ões) formada(s) ou em formação com o objetivo de garantir preservação e acesso ao público.

Nas coleções especiais da Biblioteca Universitária da Universidade Federal de Minas Gerais, por exemplo, um dos fundamentos para a formação de uma coleção especial é a sua relevância para ações de ensino, pesquisa e extensão. Nesse contexto, a seleção individualizada de livros raros, antigos e especiais considera a importância científica, histórica, estética e cultural desses documentos. Tal avaliação busca compreender e reconhecer determinado livro a partir das seguintes diretrizes:

a) Identificar a relevância da publicação para a memória da instituição.

b) Buscar informações sobre o contexto histórico, social e cultural da publicação.

c) Localizar e avaliar notícias bibliográficas em repertórios de livros raros e antigos.

d) Realizar analise material.

Os pontos escolhidos para explanação nesse Seminário são aqueles apontados nos itens "c" e "d" - a pesquisa bibliográfica e a análise do objeto bibliográfico -, compreendidos como atividades que fazem parte da atuação do bibliotecário em coleções especiais. Nosso objetivo é buscar aproximações que contextualizem os repertórios bibliográficos como instrumentos de identificação de livros raros e antigos e, do mesmo modo, discorrer sobre a análise material do livro a partir das influências da Bibliografia Material. 
Dessa forma, seguiremos com apontamentos sobre a Bibliografia, identificadas aqui como repertorial e material, em consonância com a divisão apontada por Fermín de los Reyes Gómez (2005) na qual a primeira se propõe a buscar, identificar, descrever e classificar os documentos para elaborar repertórios como instrumentos para auxiliar a pesquisa.

la bibliografía o ciencia del libro se propone buscar, identificar, describir y clasificar
los documentos para elaborar repertorios que faciliten el trabajo intelectual. Desde
esta perspectiva, los estudios y repertorios bibliográficos se centran más en la
estructura interna de los libros que en su elaboración material, por lo que los límites
son culturales y se ciñen a unas etapas históricas, que pueden variar de unos países a
otros. (REYES GÓMEZ, 2005, p. 39-40).

A segunda, a Bibliografia Material, de âmbito anglo-saxão, se dedica ao estudo da técnica de produção do livro sobre seu aspecto histórico, descritivo, analítico e crítico - e, como veremos, adotado pela Biblioteconomia para a identificação de livros antigos e também como método para auxiliar a descrição em instrumentos de apoio à pesquisa (bibliografias e catálogos, por exemplo). Essa corrente teórica "también denominada «analitical bibliography», «bibliography» se identifica con la «ciencia del libro», objeto de su estudio bajo todos sus aspectos: histórico, descriptivo, analítico, crítico y catalográfico” (REYES GÓMEZ, 2005, p. 40).

O presente texto aborda essas vertentes da Bibliografia como disciplinas fundamentais da Biblioteconomia de Livros Raros. Raphaële Mouren (2012), no livro Ambassadors of the book, referenda que os primeiros passos para a investigação sobre o livro raro e antigo, na prática profissional dos bibliotecários, perpassam pelo reconhecimento histórico da produção do livro - considerando o texto veiculado e o contexto social e cultural de sua produção; a identificação de outros exemplares tendo de um lado a necessidade de realizar análise material do livro com outros exemplares existentes; e a consulta aos repertórios de livros antigos e raros (bibliografias, catálogos, inventários institucionais e comerciais).

Ao analisar a produção intelectual da Biblioteconomia de Livros Raros no Brasil (no período compreendido entre a segunda metade do século XX e início do XXI) ${ }^{2}$ identificamos que são frequentes: a) as indicações da consulta às obras de referência sobre livros raros; e b) a necessidade do estudo do livro em sua materialidade. Desse modo, discutir sobre as correntes (repertorial e material) da Bibliografia visa compreender como elas estão relacionadas com a

\footnotetext{
${ }^{2} \mathrm{O}$ estudo da produção intelectual da Biblioteconomia brasileira sobre a temática livros raros - parte do projeto de pesquisa de mestrado de Diná Araújo sob a orientação de Alcenir Soares dos Reis no Programa de PósGraduação em Ciência da Informação da UFMG - dialoga com nossa abordagem, mas não faz parte da exposição selecionada para esse Seminário.
}

InCID: R. Ci. Inf. e Doc., Ribeirão Preto, v. 7, n. esp., p. 183-201, ago. 2016. 
Biblioteconomia enquanto disciplinas instrumentais para a pesquisa sobre o livro raro e antigo. Uma corrente auxilia com teorias e métodos de análise material e outra contribui para a identificação de livros, para a produção de repertórios e ainda retrata os usos e significados culturais e sociais do livro ao longo da história.

\section{Bibliografia}

Sem a intenção de apresentar uma historiografia dos estudos sobre a Bibliografia selecionamos alguns autores para a presente explanação. O primeiro é José Simón Díaz ${ }^{3}$ (1971) que em seu livro La Bibliografía: conceptos y aplicaciones expõe as várias vozes da Bibliografia. Um possível resumo para as vozes apontadas pelo autor são:

a) Bibliografia: lista de livros. Compreendida a partir do surgimento do livro impresso, no século XV, a bibliografia teve seu nome próprio somente no século XVII, quando Naudé e Louis Jacob deram esse nome às relações de títulos de livros, elaboradas por eruditos e livreiros.

b) Bibliografia: conceito neoclássico, século XVIII, direcionada para o conhecimento dos manuscritos.

c) Bibliografia: ciência do livro, século XVIII, compreendendo dois ramos: a produção do livro e a sua história (valores, autores, editores, catalogação, classificação, difusão...). Seguindo essa constante até o século XX, quando bibliógrafos anglo-saxões propõem estudos do livro a partir de suas características materiais, para através delas, possibilitar a autenticidade de uma edição, precisar seu local de publicação e data, por exemplo.

d) Bibliografia: ciência das bibliotecas

e) Bibliografia: ciência dos repertórios, do século XIX ao século XX.

“En 1812, Gabriel Peignot, em su Répertoire universel de bibliographie, emplea por primera vez el término <<Bibliología $>>$ para designar la Ciencia del Libro y reserva el de <<Bibliografía >> para uma de sus partes, la que estudia los repertórios" (SIMÓN DÍAZ, 1971, p. 17).

\footnotetext{
3 Renomado bibliografo espanhol do século XX, sua biobibliografia pode ser consultada em: BIOBIBLIOGRAFIA DE JOSÉ SIMÓN DÍAZ, Documentación de las ciencias de la información, n.10. Ed, Univ, Complutense. Madrid, 1986, p. 11-42. Disponível em: < https://revistas.ucm.es/index.php/DCIN/.../20451>.
} 
Em referência ao texto de Louise-Noëlle Malclès ${ }^{4}$, Simón Díaz finaliza:

La Bibliografia ocupa un sector de la Bibliología o Ciencia del libro y se propone buscar, identificar, describir y classificar los documentos impresos con el fin de constituir repertórios adecuados para facilitar el trabajo intelectual. (SIMÓN DÍAZ, 1971, p. 19).

f) Bibliografia: parte da documentação que se ocupa dos impressos

O autor ratifica que sua sistematização não representa etapas evolutivas da Bibliografia, senão interpretações divergentes, existentes até nossos dias, que formam um todo cujas partes estão intimamente interligadas.

Ainda tendo em vista os estudos sobre a Bibliografia, o próximo autor que apresentamos é Jean-Claude Utard (2002a) que dividi a Bibliografia em três facetas:

a) repertório ou listagem de títulos de publicações contendo as referências necessárias para sua identificação;

b) disciplina relativa à pesquisa, descrição e classificação de documentos escritos (textos das mais diversas naturezas) que produz repertórios que ordenam esses documentos de acordo com suas características materiais e de conteúdo.

c) técnica ou prática da bibliografia (descrita no item acima) que se propõe pesquisar e disponibilizar as referências documentais para viabilizar o acesso à informação.

Trazemos ainda para discussão Valentino Morales López (2008) que em seu livro La bibliotecología y estúdios de la información dedica um capítulo para a Bibliografia, no qual apresenta sua pesquisa sobre essa disciplina enquanto ciência

porque se trata del término de mayor antigüedad para hacer referencia ao
estudio de la información registrada y organizada por lo que su estúdio permite
conocer y comprender los antecedentes y orígenes del desarrollo de la denominación,
conceptualización y caracterización del estudio de la información registrada y
organizada. (MORALES LÓPEZ, 2008, p. 17).

Quanto a etimologia da palavra, Morales López concorda que os significados e usos da Bibliografia estão relacionados à contextos linguísticos-sociais que não correspondem à compreensão que temos hoje do que é a Bibliografia. A produção de listas de livros com vistas à sua recuperação e organização da biblioteca existe desde as bibliotecas da Antiguidade. Entretanto, para Morales López a lista enumerativa de livros não pode ser interpretada, necessariamente, como a uma bibliografia - "la actividad de elaborar libros y formar listas de

\footnotetext{
${ }^{4}$ MALCLES, Louise Noelle. La bibliographie. 2 ed. Paris: 1962. 134 p.
} 
sus títulos existía desde los griegos, pero las palavras con las que era denominada no concuerdan del todo com bibliografia" (Morales López, 2008, p. 19). Como contraponto à afirmação de Morales López, podemos considerar o posicionamento de Simón Díaz que - compreende que a Bibliografia pode se manifestar em outras tipologias de publicações como os catálogos, guias de literatura e índices, pois mesmo com denominações distintas essas podem ser reconhecidas como um produto da prática bibliográfica.

Sobre as diversas vozes da Bibiografia Isabel Torres Ramírez (2002), em seu artigo Los estúdios de bibliografia en el último cuarto del siglo, convoca Estivals para um esclarecimento:

la ciencia bibliográfica, en su doble vertiente teórica e práctica, a las circunstancias
históricas y sociales en las que se há desenvuelto y a los câmbios que se han producido
en la "superestrutuctura intelectual" de la que forma parte, la que se sitúa [...] Entre
los câmbios apuntados habría que señalar los que se han producido en los terrenos del
conocimiento y las ideologias, que han sido los responsables de que evolucionen las
clasificaciones, por ejemplo; el aumento del saber y del número de libros (títulos), que
há originado los câmbios en el tipo de bibliografías que se elaboran, la división del
trabajo bibliográfico y las diversas definiciones que se han dado de la Bibliografía
(cfr. ESTIVALS, 1978, p. $57^{5}$ apud TORRES RAMÍREZ, 2002, p. 148).

Os autores que aqui apresentamos trazem pontos de vistas diversos sobre a Bibliografia e nosso escopo não foi eleger a melhor abordagem. Entretanto, as proposições de Símon Dias (1971), que apreendem a Bibliografia enquanto ciência, técnica, arte e disciplina instrumental, podem proporcionar perspectivas diferenciadas para os estudos da Bibliografia e suas relações com áreas afins. Simón Díaz afirma que linhas tênues separam a Bibliografia, a Biblioteconomia e a Bibliofilia. Nossos esforços de aproximação dessas áreas visam alcançarmos o objetivo que estabelecemos para nossa abordagem nesse Seminário.

${ }^{5}$ ESTIVALS, Robert. La bibliologie. Paris: S. de Bibliologie et Schématisation, 1978.

InCID: R. Ci. Inf. e Doc., Ribeirão Preto, v. 7, n. esp., p. 183-201, ago. 2016. 


\section{Bibliografia e Bibliofilia: alguns apontamentos}

Roger Chartier (1998), em referência à Biblioteca de Babel de Borges aponta que o desejo de constituir uma biblioteca que reunisse todo o conhecimento do mundo foi a base para a formação das bibliotecas desde a produção da palavra escrita. Esse mesmo desejo "fundamentou a constituição de grandes "livrarias", fossem elas principescas, eclesiásticas ou particulares; ele justificou a busca tenaz de livros raros, edições perdidas, textos desaparecidos" (CHARTIER, 1998, p. 67-68). Com essa afirmação Chartier inicia o texto sobre as "Bibliotecas sem muros", no qual discute as implicações culturais para a formação de bibliotecas francesas e o papel de instrumentos mediadores (catálogos, inventários, bibliografias) nessa jornada em busca da biblioteca ideal.

Como relatam Chartier (1998) e Burke (2003, p. 153), as fontes para encontrar e/ou conhecer livros desejáveis por um colecionador eram possibilitadas pela consulta em catálogos de bibliotecas, bibliografias, livros, catálogos de vendas, livreiros, colecionadores e eruditos. E no contexto de formação das bibliotecas modernas Gabriel Naudé em Advis pour dresser une bibliothèque (1627) indicava as fontes para obter as informações sobre livros para a biblioteca ideal. Essas indicações estão especificadas, de forma mais explicita, nos capítulos 2 e 5 de seu tratado:

Capítulo 2: Sobre a maneira de se instruir e de saber sobre a formação de uma biblioteca; e

Capítulo 5: Dos meios para localizar os livros.

No quinto capítulo Naudé advertia para a consulta aos índices, tratados, livros, catálogos de bibliotecas e de livreiros, pois eram instrumentos norteadores do reconhecimento da qualidade de um livro que deveria compor uma biblioteca. Com base em Jean Viardot (1983), em seu artigo Le livre rare: collectionneurs et marchands spécialisés de Naudé à Nodier, consideramos que esses capítulos de Naudé revelam também práticas sociais e culturais para formação de bibliotecas particulares naquele período: a busca por obras de referência para instrução e orientação de colecionadores desejosos por formar bibliotecas patrimoniais.

De acordo com Yann Sordet (2002, p. 285), a Bibliofilia no final do XVII e início do XVIII, após estabelecer os critérios para a distinção de seus membros, adota um critério determinante para a consolidação do sistema de valoração das bibliotecas: a definição do livro raro. A partir do século XVII bibliógrafos produziram dezenas de bibliografias dedicadas ao 
livro raro, as quais assumiram um lugar de destaque nas práticas de Bibliofilia por produzirem notícias bibliográficas e descrições materiais dos livros, mas, sobretudo, por tornarem-se o lugar privilegiado para a definição da raridade bibliográfica.

Sordet (2002, p. 285), dentre os muitos e importantes bibliógrafos de livros raros, cita que são representativos dos cenários das práticas do colecionismo bibliográfico, do século XVIII ao XX: o alemão Johann Vogt (1753) ${ }^{6}$; os franceses Guillaume-Françoes Debure $(1763)^{7}$ e Jacques-Charles Brunet $(1860)^{8}$; e o inglês John Carter $(1952)^{9}$. Para nossa abordagem destacaremos as bibliografias de Debure e Brunet.

A Bibliographie instructive: ou traité de la connaissance des livres rares et singuliers de Guillaume-Françoes Debure, impressa em 7 volumes entre os anos 1763 à 1768 reuniu os livros ditos por Debure como os mais raros desde a República das Letras a partir da invenção da imprensa até aquele século.

Marie-Anne Merland (2002) relata que Guillaume-François Debure, herdeiro da quarta geração da família de livreiros francesa conhecida como De Bure famille, publicou o primeiro repertório bibliográfico francês exclusivo para bibliófilos. A Bibliographie Instructive foi "sistematicamente classificada de acordo com categorias gerais de livreiros em Paris" (MERLAND, 2002, p. 724b). Para cada livro ela apresentava notas de raridade das edições, atribuição dos valores de compra, orientação quanto às características que distinguem as primeiras edições das demais, as falsificações e ainda a descrição tipográfica de cada livro. A Bibliographie instructive foi organizada por assunto e seguiu o sistema bibliográfico adotado por bibliografias gerais da época, além disso apresentava uma listagem de autores e um sistema de organização bibliográfica (prática recorrente nas bibliografias após a publicação de Bibliotheca Universalis, por Conrad Gesner em 1545).

\footnotetext{
${ }^{6}$ VOGT, Johannis. Johannis Vogt Catalogus histórico-criticus librorum rariorum: jam curis quartis recognitus et copiosa accessione ex symbolis et collatione bibliophilorum per Germaniam doctissimorum adauctus. Hamburgi: Sumtibus Christiani Heroldi, 1753.

${ }^{7}$ DEBURE, Guillaume-François. Bibliographie instructive: ou Traité de la connoissance des livres rares et singuliers. Contenant un catalogue raisonné de la plus grande partie de ces livres précieux, qui ont paru successivement dans la République des lettres, depuis l'invention de l'imprimerie, jusques à nos jours. Paris: Guillaume-François DE BURE le Jeune, Libraire, 1763- 1768.

${ }^{8}$ BRUNET, Jacques-Charles. Manuel du libraire et de l'amateur de livres: contenant $1^{\circ}$ Un nouveau dictionnaire bibliographique $\ldots 2^{\circ}$ Une table en forme de catalogue raisonné .... Cinquième édititon originale entièrement refondu. Paris: Librairies de Firmin Didot, 1860-1865. 6 v. + suplemento (2v.).

${ }^{9}$ CARTER, John. ABC for book-collectors. New York: [s.n.], 1952.
} 
Debure descreveu e detalhou os conselhos para se formar uma biblioteca - a seleção, o comércio, a organização e especialmente a definição do livro raro. As publicações de Debure proporcionaram um terreno sólido e fértil para as bibliografias bibliofílicas que as sucederam.

Encerrando nossos exemplos de bibliografias, no século XIX, em 1810, o bibliófilo e livreiro francês Jacques-Charles Brunet publicou a primeira edição do Manuel du libraire et de l'amateur de livres, que teve sua quinta edição corrigida e aumentada em 1860-1865 e ainda os suplementos dessa edição foram publicados em 1878-1880.

О Manиel du libraire é uma bibliografia geral e internacional que reuniu 47.500 títulos de livros raros, preciosos e especiais, desde a origem da impressão com tipos móveis até o ano de 1850. Além das notícias bibliográficas, para cada livro, Brunet apontou o assunto abordado, o histórico das edições (legais e ilegais) e particularidades exclusivas de cada exemplar.

Metódico, preciso e instrutivo o Manuel du libraire, dentre a vasta produção de bibliografias da Bibliofilia, se inscreveu como um dos mais completos instrumentos bibliográficos de seu século. Nele os conselhos para a formação de uma biblioteca foram exaustivamente detalhados para atender os desejos da Bibliofilia.

Brunet organizou о Manuel du libraire por assunto, os autores foram ordenados pelo sobrenome e os livros com autores anônimos receberam entrada por ordem alfabética de títulos. Ele inseriu também uma tabela de classificação com base na classificação de livreiros do século XVII (como Debure). Novamente, Bibliofilia e Bibliografia produzem uma obra-modelo, o repertorio do que se deve colecionar, os valores de compra, as categorias de raridade, a organização, a classificação e os tantos demais fazeres necessários para se formar uma biblioteca.

Utard considera que o Manuel du libraire "que deu fama ao seu autor, refletindo a expansão da Bibliofilia no século XIX, é também considerado como um modelo de meticulosidade bibliográfica e a epítome das grandes bibliografias gerais deste século." (UTARD, 2002b, p. 396b). ${ }^{10}$

\footnotetext{
${ }^{10}$ Tradução nossa de: "Ce Manuel, qui fit la notoriété de son auteur, témoigne de l'expansion de la bibliophile au $X I X^{\circ}$ siècle. Il est également considéré comme un modèle de méticulosité bibliographique et l'exemple même des grandes bibliographies générles de ce siècle." (UTARD, 2002b, p. 396b).
} 


\section{Bibliografia, Bibliofilia e Biblioteconomia de Livros Raros}

Na Biblioteconomia de Livros Raros no Brasil a indicação da consulta aos repertórios bibliográficos - para identificar livros e inclusive como fonte de indicação de raridade - é recorrente na produção intelectual da Biblioteconomia de Livros Raros (manuais, apostilas de cursos técnicos, artigos, relatórios de pesquisa, relatos de experiência). Mas, quais estruturas tipológicas de obras de referência podem ser encontradas em coleções especializadas em livros raros e antigos? De acordo com Simón Díaz (1971) consideramos que essas bibliografias podem compreender:

a) bibliografia de bibliografias

b) bibliografia cronológica

c) bibliografia sistemática

1. Bibliografias (retrospectiva geral, crítica, parcial)

d) catálogos ${ }^{11}$

1. de bibliotecas institucionais

2. de bibliotecas particulares

3. coletivo

a) regionais

b) nacionais

b) institucionais

3. de exposições

4. comerciais

a) editoriais

b) livreiros

c) leilões

Em bibliotecas guardiãs de acervos patrimoniais as bibliografias bibliófilicas compõem coleções de referência sobre livros raros e antigos que, além de instrumentos de pesquisa e apoio técnico, são fontes de informação sobre os usos culturais e sociais do livro ao longo da História das Bibliotecas.

\footnotetext{
${ }^{11}$ Os catálogos são compreendidos, em nossa abordagem, dentro de um campo ampliado que é o dos repertórios bibliográficos. Nesse sentido, para a localização de títulos, os catálogos permanecem como ferramentas imprescindíveis. Reyes Gómez aponta que apesar de não fazerem parte dos repertórios bibliográficos o catálogo é uma ferramenta "que también puede ser utilizada como primer paso para la elaboración de un trabajo bibliográfico” (REYES GÓMEZ, 2005, p.55).
} 
A adoção de bibliografias de Bibliofilia para definição de raridade bibliográfica na Biblioteconomia de Livros Raros é uma questão que exige reflexões. Quais memórias serão preservadas quando um instrumento de definição de raridade caracteriza-se pelo viés da Bibliofilia? No caso de bibliotecas brasileiras, quais influências da Bibliofilia podem nublar os horizontes de compreensão do patrimônio cultural bibliográfico de regiões nas quais as publicações não são relevantes por serem colecionáveis, mas por documentarem a história e a cultura libraria local? Quais valores, por essência excludentes, da Bibliofilia podem enevoar a compreensão dos significados do livro, enquanto objeto múltiplo da memória, no século XXI?

\section{Bibliografia Material}

Wallace Kirsop define a Bibliografia Material como o "estudo material dos textos impressos" (KIRSOP, 2002, p. 275) que tem como objetivo a analise arqueológica dos livros. No início do século XX os estudantes ingleses Walter Greg e R. B. McKerrow iniciaram pesquisas direcionadas para a construção de conceitos e métodos que definiriam o corpus da bibliografia cujo objetivo era a análise material dos livros. David Finkelstein e Alistair McCleery (2014) no livro Una introducción a la historia del libro apontam que no princípio do século XX o crescente interesse dos acadêmicos sobre os primeiros textos impressos e sua produção propiciaram a criação da disciplina que ficou conhecida como Nova Bibliografia ${ }^{12}$.

La impresión de las primeras ediciones de la obra de Shakespeare, por ejemplo, fue problemática. ¿Como se podia distinguir - preguntaban los estudiosos de la literatura - entre las versiones "auténticas" de suas obras y las "alteradas"? ¿Por qué médio los investigadores podrían aceder ao texto verdadeiro tal como fue concebido por Shakespeare en los siglos XVI y XVII, dada la falta de fuentes de um manuscrito original y la existência de versiones impresas poco fiables? La respueta estaba en las metodologias propuestas por la escuela de la New Bibliography, liderada por los estudiosos como R. McKerrow (1927), W.W. Greg (1950) y Fredson Bowers (1950). El establecimiento de textos autorizados se convirtió en una cuestión de examen de la materialidade de la producción textual original, de estúdio de textos y libros como objetos físicos (determinar diferencias en tipografia, papel, tinta, métodos de impresión y cuestiones similares) para distinguir entre versiones "buenas" y "malas" de las obras." (FINKELSTEIN; MCCLEERY, 2014, p. 27).

De acordo com Finkelstein e McCleery (2014, p. 27) foram os métodos para distinguir as boas e as más versões dos fólios de Shakespeare e as conclusões para chegar a tais

12 Dentre outros autores Wallace Kirsop defende que a análise material do livro é anterior à fundação da Nova Bibliografia anglo-saxã: “l'activité est beaucoup plus ancienne, et ele s'inspire entre autres de l'érudition des incunabulistes allemands et néerlandais et des vastes connaissances amassées par la tradition bibliophilique française. Il faut donc remonter au XVIII siècle pour découvrir les origines d'une approche qui se situe dans un domaine qui s'appelle tantôt la bibliologie tantôt - à une date plus récente - la textologie. " (KIRSOP, 202, p. 276). Essa abordagem não faz parte da discussão escolhida para nossa fala nesse Seminário. 
Bibliotecas, Bibliofilia e Bibliografia: alguns apontamentos

atribuições, defendidas pelo bibliografo Alfred William em seu livro Shakespeare's fólios and quartos $^{13}$, que influenciaram McKerrow, Greg e Bowers a desenvolver os princípios gerais da nova disciplina. Para definir o campo da Nova Bibliografia Walter Greg defendia a distinção entre essa e a bibliografia repertorial:

Para evitar ambiguidades vou definir a "bibliografia" como o estudo dos livros como objetos materiais [...] A qualificação é importante. É uma espécie de cláusula filioque dirigida contra uma heresia particular; [...] porque bibliografia não tem nada a ver com o assunto ou conteúdo literário de um livro." ${ }^{14}$ (Greg, 1945).

A definição de que os "livros são meios materiais pelos quais a literatura é transmitida; portanto, a bibliografia, o estudo dos livros, é essencialmente a ciência da transmissão dos documentos literários" ${ }^{15}$ (Greg, 1932, p.113) recebeu críticas quanto à identificação desta como ciência $^{16}$. Apesar das discussões, as bases da nova disciplina estavam alicerçadas, dentre elas as proposições de princípios e métodos de análise bibliográfica desenvolvidas por Greg: um formulário de colação para padronização de descrição dos livros, com objetivo de oferecer consistência e organização aos processos de análise.

Ronald McKerrow, Fredson Bowers, Philip Gaskell e D. F. McKenzie também contribuíram para o desenvolvimento da disciplina que ficou conhecida como Bibliografia Material. Há outros bibliógrafos que colaboraram para o desenvolvimento da disciplina, contudo as pesquisas e obras desses autores são as que mais se destacaram. ${ }^{17}$ Seus trabalhos serão apresentaremos a seguir por ordem cronológica de publicação de suas obras.

No outono de 1913 McKerrow $^{18}$, em congresso direcionado para estudantes de literatura, apresentou o Notes on bibliographical evidence for literary students and editors of english works of the sixteenth and seventeenth centuries, que foi impresso como parte do

\footnotetext{
${ }^{13}$ POLLARD, A. W. Shakespeare's fólios and quartos. Londres: Methuen, 1909.

${ }^{14}$ Tradução nossa de: "To avoid ambiguity I would define "bibliography" to mean the study of books as material objects. The qualification is important. It is a sort of filioque clause directed against a particular heresy; [...] because bibliography has nothing whatever to do with the subject or literary content of the book. ". (Greg, 1945).

15 Tradução nossa de: "Books are the material means by which literature is transmitted; therefore bibliography, the study of books, is essentially the science of the transmission of literary documents" (Greg, 1932-1933, p. 113).

${ }^{16}$ Robert Darnton, historiador do livro, aponta que as críticas e discussões sobre bibliografia como ciência, a partir do texto de Greg, podem ser consultadas no artigo "Bibliography and Science, de G. Thomas Tanselle, em Studies um bibliography, vol. 27 (1974), p.62.” (Darnton, 2010, p.148).

17 As referências aos autores Greg, Mckerrow e Bowers como os fundadores da Nova Bibliografia podem ser consultadas nos periódicos: Transactions of the Bibliographical Society; Transactions of the Cambridge Bibliographical Society; Papers of the Bibliographical Society of America; Papers of the Bibliographical Society of the University of Virginia - atualmente Studies in bibliography.

${ }^{18}$ Ronald Brunlees McKerrow (1872-1940).
}

InCID: R. Ci. Inf. e Doc., Ribeirão Preto, v. 7, n. esp., p. 183-201, ago. 2016. 
décimo segundo volume do Transactions da Bibliographical Society ${ }^{19}$. Os apontamentos de McKerrow tinham como propósito apresentar aos estudantes o conhecimento sobre os processos de produção do livro para capacitá-los a analisar esse objeto a partir de seus elementos materiais, vistos como provas e vestígios de sua história. $\mathrm{O}$ enfoque de McKerrow era, especificamente, familiarizar os estudantes com os métodos de produção do livro na Inglaterra durante os anos em que Shakespeare escrevia. A partir dessa experiência ele pretendia fazer os estudantes compreenderem os demais métodos de produção do livro impresso em outros períodos e locais.

McKerrow (1928) enfatizou que seu trabalho não era um manual para estudantes de impressão, de bibliografia repertorial, nem para colecionadores - também não pretendia discutir as questões de raridade ou do comércio do $\operatorname{livro}^{20}$ - seu objetivo era analisar a relação do livro impresso com os manuscritos originais do autor por meio de evidências materiais. O primeiro passo seria avaliar impressão (imposição, primeiras impressões, modificações das técnicas de impressão), ilustrações, formatos, assinaturas, foliação e paginação. E em seguida descrever o livro; e identificar variações, erros, adições, correções, falsificações e fac-símiles.

A proposta da Nova Bibliografia alcançou a Biblioteconomia e em 1931 Arundell Esdaile $^{21}$ publicou o Manual of Bibliography seu objetivo foi publicar uma introdução à Bibliografia Material não direcionada somente aos futuros bibliógrafos, mas também para bibliotecários e colecionadores. Para isso apresentou um Manual estruturado em três enfoques:

a) os conceitos gerais da bibliografia material;

b) as características dos livros desde Gutenberg (suporte, tipografia, composição, ilustração, encadernação, colação); e

c) os arranjos e ferramentas para a descrição bibliográfica analítica.

O Esdaile's Manual of Bibliography, como ficou conhecido, teve repercussão no campo da Biblioteconomia inglesa ${ }^{22}$ sobretudo por sua circulação dentre os manuais da Library

\footnotetext{
${ }^{19}$ Em 1927 McKerrow publicou a primeira edição deste trabalho em livro. A segunda edição, com correções, foi impressa em 1928.

${ }^{20}$ It is not a hand-book for students of printing oro $f$ general bibliography. Still less is it intended for bookcollectors. I have not concerned myself in the least with rarity ou beauty or comercial value of the products of the printing-press [...] (McKerrow, 1928, p. vi).

${ }^{21}$ Arundell James Kennedy Esdaile (1880-1956), bibliotecário e bibliografo inglês, não faz parte do grupo tradicional de fundadores da disciplina. A opção por citá-lo neste trabalho deve-se ao diálogo que ele estabeleceu entre a Bibliografia Material e a Biblioteconomia.

${ }^{22}$ Em Londres, o livro de Esdaile foi publicado pela primeira vez em 1931, teve mais três edições nos anos de 1932, 1954, 1967 e duas reimpressões em 1958 e 1963. Segundo Robert L. Collison: "The most readable of all the textbook on the subject: covers all essential points." (COLLISON, Robert L., 1957, p.190).
} 
Bibliotecas, Bibliofilia e Bibliografia: alguns apontamentos

Association em Londres. O Manual de Esdaile sistematizou a proposta da Bibliografia Material para o campo da Biblioteconomia não restringindo a disciplina ao objetivo proposto por Greg e McKerrow, antes instigava a aproximação das disciplinas para auxiliar trabalhos técnicos de descrição e identificação de livros antigos.

O próximo bibliógrafo é Fredson Bowers que em 1949 publicou Principles of bibliographical description, no qual apresentou seu método para descrição de livros - inspirado na metodologia de W. W. Greg, mas com modificações a ampliações. Bowers afirmou a filiação de sua proposta, mas reconheceu que seu trabalho não abordava as mesmas questões e poderia ser interpretado como uma continuação da abordagem. O modelo metodológico de Bowers envolveu um tríplice propósito:

(1) fornecer, pormenorizadamente, um registro analítico das características físicas de um livro que serve simultaneamente como uma fonte confiável de identificação e como um meio de apresentar o livro, ausente, diante dos olhos do leitor; (2) prover uma investigação analítica e um arranjo ordenado desses fatos físicos que servem como pré-requisito para a crítica textual dos livros descritos; (3) abordar conjuntamente literatura e impressão ou a história da edição, através da investigação e registro de detalhes correspondentes à uma série de livros relacionados. (BOWERS, 1962 , p. vii $)^{23}$.

O autor inicia o livro com as definições para edição, tiragem, estado e cópia ideal. E segue tratando sobre a descrição bibliográfica por séculos (do XVI ao XVIII) e transcrição da folha de rosto, colofão e explicit, título de cabeça e título corrente. Dedica-se aos formatos e padrões de colacionamento, paginação e foliação, placas e inserções, lista de conteúdo, clichês, tipografia.

Bowers propôs um modelo metodológico de análise que o bibliografo poderia adequar para outros livros de acordo com os propósitos de determinada pesquisa. Entrementes, apesar de ratificar que sua proposta poderia ser aplicada a outras tipologias de livros, ele também reconhecia que seu método de análise foi desenvolvido tendo como objeto a produção de livros ingleses e norte-americanos.

Ao contrário de Esdaile, Bowers afirmava que sua pesquisa não estava relacionada às práticas de catalogação em bibliotecas.

\footnotetext{
${ }^{23}$ Tradução nossa de: (1) to furnish a detailed, analytical record of the physical characteristics of a book which would simultaneously serve as a trust-worthy source of identification and as a medium to bring na absent book before a reader's eyes; (2) to provide an analytical investigation and an ordered arrangement of these physical facts which would serve as the prerequisite for textual criticismo of the books described; (3) to approach both literary and printing or publishing history through the investigation and recording of appropriate details in a related series of books. (Bowers, 1962, p. vii).
}

InCID: R. Ci. Inf. e Doc., Ribeirão Preto, v. 7, n. esp., p. 183-201, ago. 2016. 
a identificação desses dois temas [bibliografia descritiva e catalogação] tem sido uma fonte de muita confusão. A catalogação de livros em bibliotecas é organizada pelas próprias bibliotecas para suas finalidades específicas e de forma adaptada para a formação prévia do seu pessoal. Este é um campo que tem pouca conexão com bibliografia descritiva acadêmica, no sentido analítico, e, portanto, eu não vou dedicar-me a essa discussão. (BOWERS, 1962, p. ix) $)^{24}$

Apesar do apontamento de Bowers e apesar do objetivo da Bibliografia Material não ser a descrição material de livros em processos de catalogação, a influência da disciplina impactou a Biblioteconomia de Livros Raros como referencial metodológica de análise do livro conforme evidenciam as publicações técnicas desse período, uma delas é o Esdaile's Manual of Bibliography ${ }^{25}$. Nas décadas seguintes, vemos a permanência da influência da Bibliografia Material nas seguintes publicações técnicas (citamos apenas alguns exemplos):

a) Descriptive Cataloging of rares books (1981) publicado pela Library of Congress.

b) Examples to accompany Descriptive Cataloging of Rares Books (1993), publicado pela Association of College and Reseach Libraries da American Library Association.

c) E no Descriptive Cataloging of Rare Material (Books), publicado pela Library of Congress em 2007, nessa publicação destacamos a obra de Philip Gaskell.

Nas décadas de 1960 e 1970 os estudos de Philip Gaskell e Donald F. McKenzie surgem como propostas de aplicação, ampliação e redirecionamento da Nova Bibliografia. Em 1972 Gaskell publicou A new introduction to bibliography declaradamente como um seguimento da obra de McKerrow, não uma revisão, mas um novo livro a partir das ideias iniciadas pelo mestre. Após mais de quarenta anos da publicação do McKerrow e apesar de suas justificativas, Gaskell inova na ampliação dos conceitos apresentados em 1928 e também por se aprofundar na produção mecânica do livro no período de 1800 a 1950 (período não abordado com profundidade pelos bibliógrafos que o antecederam).

Mas, foi em 1966 que houve um grande impacto no campo da Nova Bibliografia, produzido pela obra de Donald F. McKenzie, aluno de Philip Gaskell que seguiu os preceitos da disciplina analisando os livros produzidos pela editora da universidade de Cambridge. $\mathrm{O}$ livro publicado a partir da tese The Cambridge University Press, 1696-1712 (1966), foi saudado como uma das obras mais rigorosas já escritas na tradição de Greg e McKerrow” (Darnton,

\footnotetext{
${ }^{24}$ Tradução nossa de: the identification of these two subjects has been a source of much confusion. The cataloguing of books in libraries is organized by the libraries themselves for their specific purposes and in a manner adapted to the prior training of their personnel. This is a field having little connection with scholarly descriptive bibliography in the analytical sense, and hence I do not concern myself with it. (Bowers, 1962, p. ix).

${ }^{25}$ Outros exemplos:

COWLEY, John D. Bibliographical description and cataloguing. London: Grafton, 1939.

BÜHLER, Curt F. MCMANAWAY, James G. WROTH, Lawrence C. Standards of bibliographical description. London; Cumberlege: University of Philadelphia, 1949.
} 
Bibliotecas, Bibliofilia e Bibliografia: alguns apontamentos

2010, p. 151). A pesquisa de McKenzie revelou que as práticas de produção do livro não aconteceram rigorosamente como as teorias e métodos que os pais da Nova Bibliografia apontavam em seus tratados, no sentido de que não havia uma imutabilidade no processo de produção dos livros. "Bibliógrafos anteriores haviam presumido que cada livro avançava pela cadeia de produção seguindo um padrão consistente e linear" (Darnton, 2010, p.152). Ao publicar, em um ensaio em 1969, que as avaliações sobre os tipógrafos estavam erradas, McKenzie causou grande tensão na área, pois ele provou que as lógicas estabelecidas até então não correspondiam às realidades das tipografias inglesas. Em outras palavras, afirmar a regularidade e precisão dos modos de impressão e composição do livro era um equívoco, pois as ações dos atores que produziam o livro não eram fixas, antes correspondiam a uma série de fatores que não poderiam ser determinados sem analisar o contexto da casa de impressão como um todo e das relações sociais e culturais ali vivenciadas.

McKenzie parecia expor uma falha geológica que atravessava todo o seu campo de estudos [...] a produção nas gráficas do início da era moderna não seguia o padrão regular atribuído a elas pela bibliografia ortodoxa (Darnton, 2010, p.154-155).

A Nova Bibliografia, até então, ignorava o contexto social da produção dos textos. A grande contribuição de McKenzie para a disciplina, além de suas descobertas, foi a convocação dos bibliógrafos para a análise sociologia dos textos.

McKenzie proponía que los investigadores fueran más allá de la interpretación de los textos como meros produtos de las intenciones del autor, o incluso solamente como efectos de las examinaciones cuantitativas y macrohistóricas de las tendências de las editoriales e imprentas, y se dirigieran hacia un estúdio de los textos como produtos mediados en los cuales uno podia encontrar trazos de un sentido económico, social, estético y literario. (FINKELSTEIN; MCCLEERY, 2014, p. 32).

As obras dos fundadores da Bibliografia Material anglo-saxã são referência para o estudo do livro como objeto material, com influências marcantes para a crítica literária e com McKenzie, especialmente, para a História do Livro. As influências da Bibliografia Material também podem ser percebidas na Biblioteconomia. Esdaile foi um dos precursores do diálogo entre a Bibliografia Material e a Biblioteconomia, suas publicações comprovam as relações iniciais e posteriores que foram estabelecidas entre a Nova Bibliografia e a Biblioteconomia inglesa e norte-americana no século XX.

A identificação de livros por meio de análise material é fundamental para profissionais que atuam em coleções especiais e acervos antigos. Ainda são necessárias pesquisas que apontem quais as influências da Bibliografia Material na Biblioteconomia de Livros Raros no Brasil. 


\section{Considerações finais}

Anne Welsh (2012), em Experimental learning in historical bibliography, enfatiza a importância da bibliografia enquanto disciplina que contribui para a formação do bibliotecário na atualidade. Ela detalha a experiência do ensino de pós-graduação sobre Coleções Especiais e Livros Raros destacando que as habilidades e conhecimentos do bibliotecário dessa área têem como fundamentos teóricos: a bibliografia, a biblioteca e a bibliografia. Welsh considera o ensino da Bibliografia essencial para a formação do profissional que irá manter contato permanente com os livros raros, antigos e especiais.

A atribuição de raridade baseada em repertórios bibliográficos da Bibliofilia em bibliotecas institucionais brasileiras é uma prática recorrente ${ }^{26}$. Tais repertórios poderiam ser adotados sem se perder de vista a contextualização histórica, cultural e social das bibliografias. Analisar criticamente o uso das bibliografias da Bibliofilia, enquanto instrumentos que ratificam a atribuição de raridade, busca compreender as definições postuladas nas páginas e entrelinhas desses repertórios a partir de uma reflexão: $\mathrm{O}$ que quer dizer aquele que diz livro raro?

Para além da raridade, o trabalho de descrição bibliográfica e/ou catalográfica de livros raros e antigos requer a consulta a várias bibliografias, para comparação de descrições referenciais ou para identificação de edições, títulos, autores, locais de impressão ou tipógrafos. Essas bibliografias possibilitam ao bibliotecário um panorama privilegiado sobre a circulação de livros nos últimos quatro séculos. Em especial, a pesquisa sobre as bibliografias de livros raros e antigos pode contribuir para a formação continuada do bibliotecário-pesquisador que atua em acervos bibliográficos patrimoniais.

Por sua vez a Bibliografia Material enquanto disciplina instrumental direcionada para a pesquisa sobre o livro impresso contribuiu na produção de manuais técnicos da Biblioteconomia. Por meio de formulários de descrição ${ }^{27}$ é possível compreender e descrever a estrutura do objeto livro. Entretanto o domínio das teorias e métodos de análise da Bibliografia Material extrapolam a descrição para catalogação, seu alcance se dá também na capacitação

\footnotetext{
${ }^{26}$ Inferência que tem por base pesquisa das autoras em manuais para o tratamento de livros raros no Brasil, publicados a partir do século XX.

27 Também identificado como formulário de colação, ele visa o detalhamento da descrição do livro por meio de suas características materiais evidenciadas: na encadernação, na tipografia (tipos e ornamentos); no papel, nas ilustrações, na paginação e na foliação; nas assinaturas e reclamos; no formato; nos modos de impressão, dentre outros.
}

InCID: R. Ci. Inf. e Doc., Ribeirão Preto, v. 7, n. esp., p. 183-201, ago. 2016. 
profissional para o conhecimento das materialidades do livro potencializando a interlocução usuário-bibliotecário-usuário - por meio de instrumentos mediadores para a pesquisa e/ou no serviço de referência especializado. A análise material do livro permite ainda ao bibliotecáriopesquisador desenvolver ações específicas de preservação de acervos.

Concluímos com a fala de Utard: "em uma sociedade da informação, o futuro da bibliografia encontra-se na mediação que ela possibilita entre usuários, documentos e conteúdo" (UTARD, 2002a, p. 275) ${ }^{28}$.

\section{Referências}

BOWERS, F. T. Principles of bibliographical description. 2.ed. New York: 1962. 505 p.

BURKE, P. Uma história social do conhecimento I: de Gutenberg a Diderot. Rio de Janeiro: Jorge Zahar, 2003. 241 p.

CHARTIER, R. A ordem dos livros: leitores, autores e bibliotecas na Europa entre os séculos XIV e XVIII. 2. ed. Brasília: Ed. UnB, 1998. 111 p.

COLLISON, R. L. Book collecting: an introduction to modern methods of literary and bibliographical detection. London: 1957. $244 \mathrm{p}$.

DARNTON, R. A questão dos livros: passado, presente e futuro. São Paulo: Companhia das Letras, 2010. $231 \mathrm{p}$.

ESDAILE, A. J. K. Esdaile's manual of bibliography. 4. ed., rev. London: 1967. 336 p.

FERNÁNDEZ VALLADARES, M. Análisis material y control bibliográfico del libro antiguo: un ejemplo a propósito de la obra de Martín de Frías. Revista General de Información y Documentación, Madrid, v. 8, n. 1, p. 11-37, 1998.

FINKELSTEISN, D.; MCCLEERY, A. Una introducción a la historia del libro. Buenos Aires: Paidós, 2014. 296 p.

GALBRAITH, S. K.; SMITH, G. D. Rare book librarianship: a introduction and guide. Santa Barbara: Libraries Unlimited, 2012. 185 p.

GASKELL, P. A new introduction to bibliography. New York: Oxford Univ., 1972. 438 p.

GREG, W. W. Bibliography: a apologia. Transactions of the Bibliographical Society, 19321933, p. 113-143.

\footnotetext{
${ }^{28}$ Tradução nossa de: “Dans une société de l'information, l'avenir de la bibliographie réside dans la médiation qu'elle permet entre utilisateurs, documents et contenus. (Utard, 2002a, p. 275).
} 
Bibliography: a retrospect. In: The bibliographical society: 1892-1942,

Bibliographical Society, 1945.

KIRSOP, W. Bibliographie matérielle. In: FOUCHÉ, P.; PÉCHOIN, P.; SHUWER, P. (Dir.) Dictionnaire encyclopédique du livre. Paris: Éditions du Cercle de la Librarie, 2002, v.1, p. 275-276.

MCKERROW, R. B. An introduction to bibliography for literary students. 2.ed. Oxford: 1928. $359 \mathrm{p}$.

MERLAND, M. A. Debure ou De Bure, famille. In: FOUCHÉ, P.; PÉCHOIN, P; SHUWER, P. (Dir.) Dictionnaire encyclopédique du livre. Paris: Éditions du Cercle de la Librarie, 2002, v. 1, p. 723-725.

MORALES LÓPEZ, V. La bibliotecología y estúdios de la información: análisis históricoconceptual. México: El Colegio de México, Biblioteca Daniel Cosío Villegas, 2008. 247 p.

MOUREN, R. (Ed.). Ambassadors of the book: competences and training for Heritage Librarians. Berlim; Boston: De Gruyter Saur; IFLA, 2012. 195 p.

PINTO, M. C. B. F. Catálogos \& bibliografias: evolução histórica do trabalho de controle bibliográfico. Revista da Escola de Biblioteconomia da UFMG, Belo Horizonte, v. 16, n. 2, p. 143-158, set. 1987.

REYES GÓMEZ, F. El libro moderno desde la bibliografia material y la biblioteconomia. Ayer: revista de historia contemporánea, Madrid, v. 58, n. 2, p. 35-56, 2005.

SIMÓN DÍAZ, J. La bibliografía: conceptos y aplicaciones. Barcelona: Planeta, 1971. 331p.

SORDET, Y. Bibliophilie. In: FOUCHÉ, P.; PÉCHOIN, P.; SHUWER, P. (Dir.)

Dictionnaire encyclopédique du livre. Paris: Éditions du Cercle de la Librarie, 2002, v.1, p. 281-286.

TORRES RAMÍREZ, I. Los estúdios de bibliografia en el último cuarto del siglo XX. Documentación de las Ciencias de la Información, Madrid, v. 25, p.147-165, 2002.

UTARD, J. C. Bibliographie. In: FOUCHÉ, P.; PÉCHOIN, P.; SHUWER, P. (Dir.)

Dictionnaire encyclopédique du livre. Paris: Éditions du Cercle de la Librarie, 2002a, v.1, p. 273-275.

BRUNET, J. C. In: FOUCHÉ, P.; PÉCHOIN, P.; SHUWER, P. (Dir.) Dictionnaire encyclopédique du livre. Paris: Éditions du Cercle de la Librarie, 2002b, v.1, p. 396-397.

VIARDOT, J. Le livre rare: collectionneurs et marchands spécialisés de Naudé à Nodier. Bulletin du bibliophile, n.2, 1983, p.157-173.

WELSH, A. Experimental learning in historical bibliography. In: MOUREN, R. (Ed.). Ambassadors of the book: competences and training for Heritage Librarians. Berlim; Boston: De Gruyter Saur; IFLA, 2012. p.147-162. 